\title{
The effect of nocturnal wear of complete dentures on sleep and oral health related quality of life: study protocol for a randomized controlled trial
}

\author{
Elham Emami ${ }^{1,2^{*}}$, Phan The Huy Nguyen ${ }^{1}$, Fernanda R Almeida ${ }^{3}$, Jocelyne S Feine ${ }^{2}$, Igor Karp ${ }^{1,4}$, Gilles Lavigne ${ }^{1}$ \\ and Nelly Huynh ${ }^{1}$
}

\begin{abstract}
Background: Edentulism and sleep disturbance are chronic conditions that are common in older people and have serious adverse consequences for their functioning and quality of life. Edentulism can disturb sleep through the alteration of the craniofacial structure and surrounding soft tissue. However, the effect of prosthetic rehabilitation of edentulism on sleep quality is still not well understood. The objectives of this study are to test whether nocturnal denture wear affects sleep quality, daytime sleepiness, and the oral health related quality of life of edentate older people with moderate to severe sleep apnea, and to identify modifiers of effect of nocturnal denture wear.

Methods/design: We will carry out a single-blind randomized cross-over trial. Seventy edentate older people with moderate to severe obstructive sleep apnea will be enrolled. The study participants will be assigned to wear and not wear their dentures on alternate periods of 30 days. The outcome measures will be sleep quality (assessed by portable polysomnography), daytime sleepiness (assessed by the Epworth Sleepiness Scale), and oral health related quality of life (assessed by validated questionnaire). A number of characteristics (sociodemographic, oropharyngeal morphology, oral and prosthesis characteristics, and perceived general health quality of life) will be assessed by means of clinical examination, 3D imaging of the craniofacial structure, and validated questionnaires at baseline. Linear mixed effects regression models for repeated measures will be fitted to test the study hypotheses. The main analyses will be based on the intention-to-treat principle. To assess the robustness of the findings to potential incomplete adherence, sensitivity analyses will be conducted while applying the per-protocol principle.
\end{abstract}

Discussion: This practice-relevant evidence could represent a preventive approach to improve sleep characteristics of the older population and improve their well-being and quality of life.

Trial registration: ClinicalTrials.gov NCT01868295.

Keywords: Complete denture, edentulism, obstructive sleeping apnea, oral health related quality of life, sleep disorders, sleep quality

\section{Background}

The worldwide population is rapidly aging, with the majority of older people living longer than previous generations [1]. Aging substantially increases the risk of tooth loss and sleep disturbance. In Canada, about one in four people aged 65 and older is completely toothless [2], and

\footnotetext{
* Correspondence: elham.emami@umontreal.ca

'Faculty of Dentistry, Université de Montréal, 2900 Edouard-Montpetit, Montreal, QC H3T 1J4, Canada

${ }^{2}$ Faculty of Dentistry, McGill University, 3550 University Street, Montreal, QC H3A 2A7, Canada

Full list of author information is available at the end of the article
}

nearly half of all older people complain of disturbed sleep [3,4]. These two chronic conditions have serious adverse consequences for well-being, functioning, and quality of life, and place a significant burden on the health care system [5-8]. The costs associated with sleep disturbance and tooth loss are also substantial [7,9-12].

The relationship between edentulism and sleep disturbance and sleep-disordered breathing has been well documented [13,14]. In fact, anatomical changes associated with edentulism and decrease in the vertical dimension of occlusion can negatively influence sleep and lead 
to obstructive sleep apnea [13-18]. Loss of the vertical dimension of occlusion leads to a forward and upward mandibular position associated with a backward shift in the supine position $[16,19]$. This rotational movement of the mandible favors a shift of the tongue and soft palate against the posterior pharyngeal wall. The reduction in the retropharyngeal space associated with impaired function of the upper airway dilatation muscles results in upper airway resistance, and diminished response to negative pressure stimulation [20-22]. Moreover, age-specific compromised pharyngeal anatomy, upper airway mucosal sensory dysfunction, and a decline in pharyngeal sensory discrimination and reflexes have been proposed as being responsible for the vulnerability of edentate elders to airway collapse [23-25]. Furthermore, the literature suggests that there is a possible association between sleep disturbance and wearing a complete denture during sleep, which may explain the mechanism underlying the relationship between obstructive sleep apnea and edentate individuals $[26,27]$. One hypothesized effect was that the use of a denture during sleep may lead to open bite and mouth breathing with a decrease in the tone of the pharyngeal muscles, thus leading to the development or worsening of obstructive sleep apnea [28]; an alternative hypothesis holds that sleep quality and pharyngeal patency are maintained by nocturnal denture use. Moreover, this denture effect appears to be different between healthy edentate older people and those with sleep disturbances [29]. However, there is a general belief amongst oral health care professionals that edentate individuals should remove their dentures at night. In fact, numerous studies have demonstrated that long-term nocturnal wearing of dentures can reduce the protective effect of saliva and obstruct good oxygenation of the oral mucosa, which makes it less resistant to mechanical and microbiological aggression, thus increasing the risk of chronic inflammatory changes within the mucosa [30-32]. This leads to an increased risk of traumatic ulcers, denture stomatitis, and alveolar bone resorption in the edentate population [33-37].

However, tooth loss and not wearing dentures at night have not been recognized as a risk factor for sleep disturbance and obstructive sleep apnea. Furthermore, the limited quality of studies on this topic (graded as level $\leq 3$ on the Oxford level of grade of evidence) [38] do not permit clinicians to engage in evidence-based clinical decision-making. This lack of knowledge poses legal and ethical problems for clinicians and other dental professionals who are involved in the care of the growing edentate population.

To enable development of clinical practice guidelines, solid evidence is required. Specifically, a rigorous randomized trial is needed to help determine the effects of denture wearing on patient-relevant outcomes [28,39-41].

To address this need, we have designed a single-blind randomized cross-over trial. The first objective of the study is to test whether nocturnal denture wear has an effect on sleep quality and daytime sleepiness of edentate older people with moderate to severe sleep apnea. The second objective is to test whether nocturnal denture wear has an effect on the oral health related quality of life of edentate older people with moderate to severe sleep apnea. The third objective is to identify modifiers of the putative effects of nocturnal denture wear.

\section{Methods/design}

The study protocol was approved by the Research Ethics Board of Health of the Université de Montréal (Project 13-076-CERES-D). The trial is registered in the US Clinical Trials Registry NCT01868295.

\section{Recruitment process}

Participants will be recruited from the area of metropolitan Montreal. Participants will be recruited through the research, prosthodontics, and sleep apnea clinics of the Université de Montréal, associated hospitals, geriatric institutes, and private sleep clinics.

The research coordinator will contact the patients in person at the clinics with a study information brochure to invite them to participate in the trial. Potential study participants will be asked to contact a research coordinator via a dedicated phone number with voicemail. The research coordinator will describe the study in general terms and assess major inclusion criteria, and the study candidates will be invited to an in-person information and screening session. During this session, the research coordinator will inform these potential participants of the general health risks associated with obstructive sleep apnea and will explain all aspects of the study, using a PowerPoint presentation and a study brochure. The interested participants will be screened for eligibility for inclusion in the study. Eligible participants will be asked to read and sign a consent form. Informed consent will be obtained from each eligible participant before proceeding with the trial.

\section{Inclusion and exclusion criteria Inclusion criteria}

To be considered for inclusion in the study, the subject must: (1) be aged 65 years or older; (2) have worn a complete set of removable dentures in the past year but not have worn the dentures during sleep in that period; (3) have an Apnea-Hypopnea Index (AHI) score of at least 15 at screening; (4) have an adequate understanding of written and spoken English or French; (5) be able to understand and respond to the questionnaires used in the study; (6) agree to follow the research study instructions; (7) agree to adhere to the allocated sequence of interventions; (8) consume no alcohol and (9) not work late at night on the day before polysomnography. 


\section{Exclusion criteria}

The participants are excluded if they: (1) have an AHI score less than 15; (2) have any severe cardiologic, neurologic, psychological, or psychiatric condition, respiratory disease, acute airway infection, or any other health condition that jeopardizes sleep; (3) score 24 or less on the Mini-Mental State Evaluation [42]; (4) regularly consume more than two (for women) or three (for men) alcoholic beverages per day; (5) are taking medication or any illicit drug that will affect sleep architecture or respiratory muscle activity (that is, hypnotics, psychostimulants, anticonvulsant, or antipsychotics); (6) are receiving regular continuous positive airway pressure therapy or nocturnal supplemental oxygen; (7) have sleepiness deemed to be unsafe and requiring urgent treatment; or (8) feel that the trial would negatively influence their private life.

Intervention, randomization, allocation concealment, and sequence generation

A single-blind randomized cross-over clinical trial will be conducted. The trial will have two sequences and two periods (balanced design).
Eligible study participants will be randomly assigned to wear or not wear their complete dentures at night, alternately, for two periods of 30 days (Figure 1). Minimal or no carry-over effect is expected based on the action of the postulated mechanism of intervention [28] (additional analyses of raw data from research team member FRA: Grizzle's model [43] sequence effect $P=0.8$, period effect $P=0.9$, intervention effect $P=0.002)$. Therefore, no wash-out period was deemed necessary.

To achieve a balanced allocation of participants in each sequence, a permuted block randomization with varying block sizes using SAS ${ }^{\oplus}$ PROC PLAN will be used [44-51]. Randomization and administration of opaque sequential envelopes will be carried out off-site. The sleep technologist will deliver these envelopes to study participants at their homes. Each participant will receive a sequentially numbered, sealed, opaque, tamper-proof envelope indicating the sequence of intervention, and intervention will start on the same day (one week after baseline assessment). All the investigators, the research coordinator, and the scoring service providers will be blinded to the

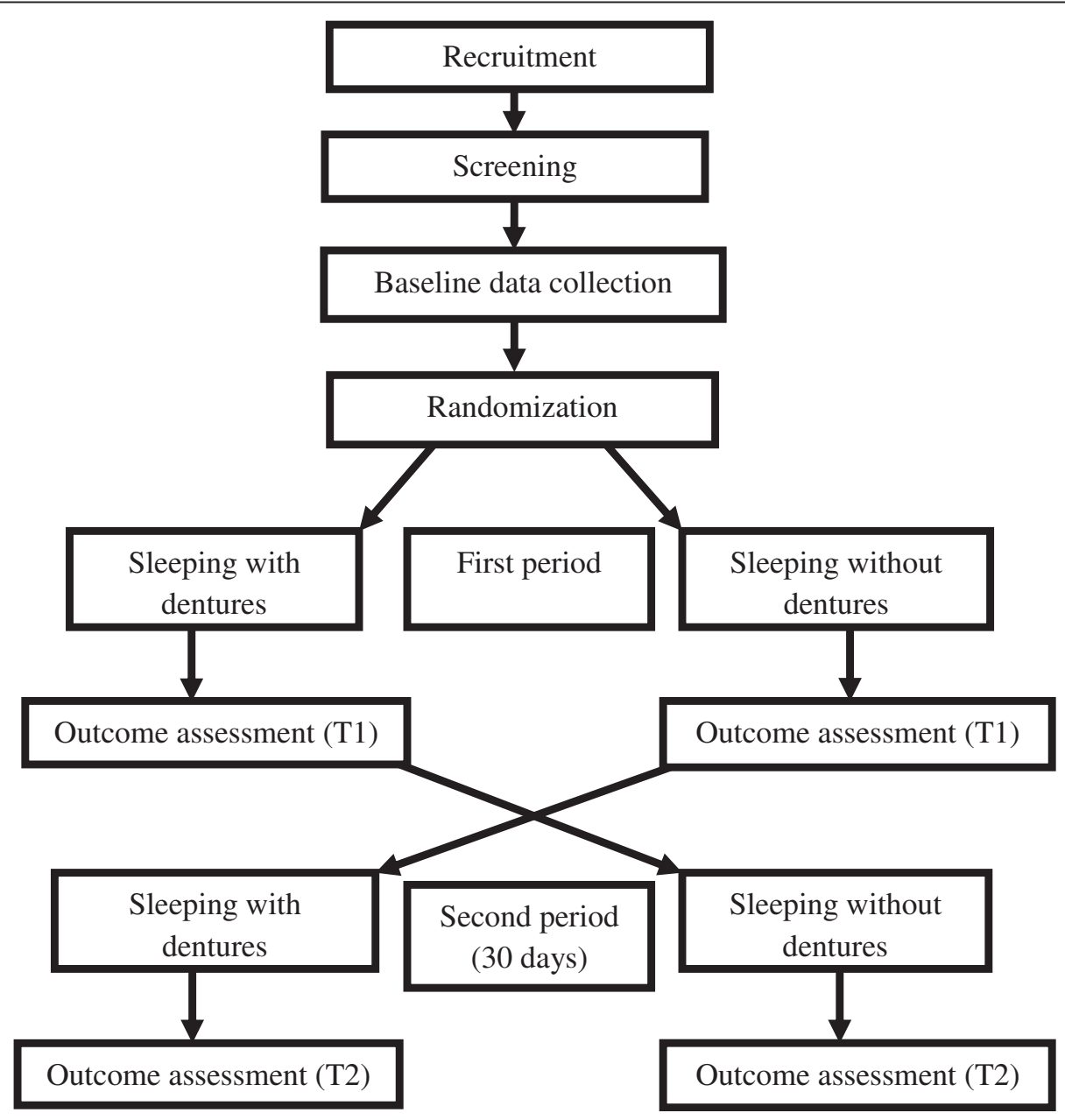

Figure 1 Trial design. 
intervention assignment. Data will be gathered, measured, recorded, and entered in a blinded fashion. Blinding will be lifted once data analysis is complete. Although it is not possible for the participants to be 'blind' to the intervention, they will be asked not to discuss their interventions with any research staff. Any question from participants during the intervention period will be answered by two independent prosthodontists and, if necessary, a sleep clinician, as these individuals will not be involved in data collection or data analyses.

\section{Data collection}

Persons who consent to participate in the study will be invited to visit the clinical research laboratories of the Faculty of Dental Medicine at the Université de Montréal at their convenience. During this visit, one trained and calibrated research trainee will conduct baseline data collection, including a clinical examination, administration of study questionnaires, and cone-beam computed tomography (CBCT) (NewTom 5G CBCT, QR S. r.l.-Verona, Italy), as described. Then, in the same week, they will undergo one baseline portable overnight recording (level II polysomnography) [52]. Follow-up data will be collected at the end of each period by the sleep technologist at home by means of one portable overnight recording and the outcome questionnaires. The sleep technologist will install the device at the participants' homes on the evening of recording, verifying electrode impedance and signal quality. This approach will allow us to maximize the participation of older people and will increase their adherence to the study procedures [53].

\section{Primary outcome measures}

The selection of the outcomes was based on a literature review and consultation with experts in sleep and oral health disease [54,55].

The primary outcome is a change in sleep quality, as measured by the AHI index. This index is a marker of sleep quality that represents the number of apneic and hypopneic incidents per hour of sleep [56]. The AHI index will be measured using diagnostic portable polysomnography units for overnight home use [57]. Standard polysomnography measurements will include total sleep duration, sleep efficiency, sleep onset latency, electroencephalogram arousal index, spontaneous arousals, and sleep-stage distribution. Upon return of the device, polysomnographic data will be downloaded and scored using REMLogic software (Embla Inc., Canada) to assess AHI, snoring index, respiratory disturbance index, flow limitation, respiratory efforts related arousals, and average and minimal oxygen saturation. These respiratory events will be scored by Sleep Strategies Inc. (Canada), according to American Academy of Sleep Medicine guidelines [58].

\section{Secondary outcome measures}

Secondary outcomes will be changes in daytime sleepiness and oral health related quality of life.

The Epworth Sleepiness Scale (ESS) will be used to assess perceived daytime sleepiness. The ESS is an eightitem, four-point scale (0 to 3 ) with strong internal consistency (Cronbach's $\alpha=0.81$ ) and half-split reliability $(r=0.82)$ [59]. Participants will be asked to rate their chance of dozing in eight different sedentary situations. Scores of 10 or more suggest excessive daytime sleepiness.

Oral health related quality of life will be measured by means of the Oral Health Impact Profile (OHIP-20) [60]. This instrument is a disease-specific measure of people's perceptions of the impact of denture wear on physical, psychological, and social aspects of their quality of life. This validated and highly reliable $(\alpha=0.88)$ oral health disease-specific instrument has been widely used in geriatric dental research [61-63] and has been tested and validated in English- and French-speaking Canadians for cross-cultural validity. The range of the scale is 20 to 120 points, with lower scores indicating a better oral health related quality of life $[60,64]$.

The primary and secondary outcome measures will be determined at baseline and at the end of each 30-day period.

\section{Covariates}

We will also collect data on sociodemographic, medical, and anthropometric (weight, height) characteristics, oropharyngeal morphology (measured by a three-dimensional imaging system, CBCT), as well as edentulism-associated characteristics (vertical dimension of occlusion according to prosthodontic standard criteria, history of tooth loss, history of denture use, and nocturnal denture wear) [65] and general health. Perceived general health will be assessed using the Short Form-36 (SF-36) [66]. This is a generic self-administered questionnaire consisting of eight multi-item subscales: physical functioning, social functioning, role limitations due to physical health problems, and role limitations due to emotional problems, mental health, vitality, pain, and general health perceptions. The SF-36 has excellent internal consistency and discriminates between individuals with and without chronic disease [66-68]. The computerized scoring system will be used according to the user's manual, in which higher scores represent a better condition [69].

\section{Sample size justification}

Assuming that (i) the minimal clinically important difference in the AHI score between the two interventions is 5 events per hour (based on the opinion of expert clinicians, Delphi method) [70], (ii) the standard deviation of the distribution of the difference in AHI score between interventions is 10.6 events per hour (based on 
estimates from our pilot data) [28], and (iii) the drop-out rate is $10 \%$ (based on our pilot data), a sample size of 70 study participants will ensure a 0.90 power to reject the null hypothesis if it is indeed false, at a two-sided Bonferroniadjusted $\alpha$ level of 0.0167 (to account for the three study outcomes).

The sample size of 70 would ensure a power of more than 0.90 to detect a difference of 2.5 units in the mean ESS score (assuming that the standard deviation is 3.5 units) [71], and a difference of 17 units (minimal clinically important difference) [72] in the mean OHIP score (assuming that the standard deviation is 23.8 units) [73], at a two-sided Bonferroni-adjusted $\alpha$ level of 0.0167 [74,75].

\section{Statistical analysis}

Descriptive analyses for all variables will be performed. In case of apparent material deviations from normality, the distributions of the dependent variables will be normalized by appropriate transformations.

Mixed linear models will be fitted using SAS Proc Mixed (SAS version 9.3, SAS Institute Inc., USA) to test the associations between the intervention and each of the study outcomes [76]. The model will include variables for intervention, randomization sequence, period, and baseline value of the study outcome as fixed effects and subject as a random effect. Hypotheses concerning model parameters will be tested by Wald tests with an approximate $F$ null distribution.

To test for potential modification of the impact of the intervention by determining the presence of sleep disturbance at baseline, and the degree of sleep disturbance at baseline, we will introduce a series of interaction terms between the intervention status and each of these characteristics (one at a time) into the above-described linear models.

All of the analyses will be carried out in accordance with the intention-to-treat principle, and various strategies will be contemplated, to account for post-randomization missing data in the case of non-balanced missing data or attrition of more than $10 \%$ of participants. However, in the sensitivity analyses, we will also carry out per-protocol analyses to assess the robustness of our findings to potential incomplete adherence: in particular, patients with major protocol violations or poor adhere will be excluded.

\section{Discussion}

This research could inform planning for a preventive approach to improve sleep characteristics of the older population and, thereby, improve well-being and quality of life. The evidence produced by this trial will assist in producing truly evidence-based practice guidelines used by primary care providers, dentists, and sleep medicine specialists, who provide care for the millions of edentate older people around the world [56].

\section{Trial status}

The project is currently in the recruitment phase.

\section{Abbreviations}

AHI: Apnea-Hypopnea Index; CBCT: cone-beam computed tomography; ESS: Epworth Sleepiness Scale questionnaire; OHIP-20: Oral Health Impact Profile questionnaire; SF-36: Short Form-36 Health Survey questionnaire.

\section{Competing interests}

The authors declare that they have no competing interests.

\section{Authors' contributions}

$\mathrm{EE}, \mathrm{NH}$, and PTHN drafted the manuscript. EE, NH, and GL participated in the conception, design and coordination of the study. FRA, JSF, and IK helped revised the manuscript and participated in the conception and design of the study. All the authors revised and approved the final manuscript for publication.

\section{Acknowledgements}

The trial is funded by Canadian Institutes of Health Research (grant number: 325899) and is supported by the facilities of Université de Montréal, Quebec, Canada. The authors would also like to acknowledge the study collaborators and knowledge users: Matthieu Schmittbuhl, Frédéric Series, Julie Carrier, Louis de Koninck, and Pierre de Grandmont. The authors are grateful for the willing participation of study participants.

\section{Author details}

${ }^{1}$ Faculty of Dentistry, Université de Montréal, 2900 Edouard-Montpetit, Montreal, QC H3T 1J4, Canada. 'Faculty of Dentistry, McGill University, 3550 University Street, Montreal, QC H3A 2A7, Canada. ${ }^{3}$ Faculty of Dentistry, University of British Colombia, \#103 - 2786W 16th Ave, Vancouver, BC V6K 4M1, Canada. ${ }^{4}$ Schulich School of Medicine and Dentistry, University of Western Ontario, 1151 Richmond Street, London, ON N6A 5C1, Canada.

Received: 25 July 2014 Accepted: 9 September 2014 Published: 13 September 2014

\section{References}

1. Department of Economic and Social Affairs - Population Division: World Population to 2300. New York: United Nations Publication; 2004.

2. Health Canada Report of the Findings of the Oral Health Component of the Canadian Health Measures Survey 2007-2009. Ottawa, ON: Ministry of Health 2010

3. Ancoli-Israel S: Sleep and its disorders in aging populations. Sleep Med 2009, 10(Suppl 1):S7-S11.

4. Ancoli-Israel S, Ayalon L, Salzman C: Sleep in the elderly: normal variations and common sleep disorders. Harv Rev Psychiatr 2008, 16:279-286.

5. Jean-Louis G, Kripke DF, Ancoli-Israel S: Sleep and quality of well-being. Sleep 2000, 23:1115-1121.

6. Zeithhofer J, Schmeiser-Rieder A, Tribl G, Rosenberger A, Bolitschek J, Kapfhammer G, Saletu B, Katschnig H, Holzinger B, Popovic R, Kunze M: Sleep and quality of life in the Austrian population. Acta Neuro/ Scand 2000, 102:249-257.

7. Hossain $\mathrm{J}$, Shapiro CM: The prevalence, cost implications, and management of sleep disorders: an overview. Sleep Breath Schlaf Atm 2002, 6:85-102.

8. Rakel RE: Clinical and societal consequences of obstructive sleep apnea and excessive daytime sleepiness. Postgrad Med 2009, 121:86-95.

9. Hillman DR, Murphy AS, Pezzullo L: The economic cost of sleep disorders. Sleep 2006, 29:299-305.

10. Kapur KK, Garrett NR, Hamada MO, Roumanas ED, Freymiller E, Han T, Diener RM, Levin S, Wong WK: Randomized clinical trial comparing the efficacy of mandibular implant-supported overdentures and conventional dentures in diabetic patients. Part III: comparisons of patient satisfaction. J Prosthet Dent 1999, 82:416-427.

11. Vernazza C, Heasman P, Gaunt F, Pennington M: How to measure the cost-effectiveness of periodontal treatments. Periodontol 20002012 , 60:138-146

12. The Canadian Centre for Policy Alternatives: Putting Our Money Where Our Mouth Is: The Future of Dental Care in Canada. Ottawa, ON: 2011. http:// www.policyalternatives.ca/sites/default/files/uploads/publications/National\% 200ffice/2011/04/Putting\%20our\%20money\%20where\%20our\%20mouth\% 20is.pdf 
13. Bucca C, Carossa S, Pivetti S, Gai V, Rolla G, Preti G: Edentulism and worsening of obstructive sleep apnoea. Lancet 1999, 353:121-122.

14. Bucca C, Cicolin A, Brussino L, Arienti A, Graziano A, Erovigni F, Pera P, Gai V, Mutani R, Preti G, Rolla G, Carossa S: Tooth loss and obstructive sleep apnoea. Respir Res 2006, 7:8.

15. Erovigni F, Graziano A, Ceruti P, Gassino G, De Lillo A, Carossa S: Cephalometric evaluation of the upper airway in patients with complete dentures. Minerva Stomatol 2005, 54:293-301.

16. Gassino G, Cicolin A, Erovigni F, Carossa S, Preti G: Obstructive sleep apnea, depression, and oral status in elderly occupants of residential homes. Int J Prosthodont 2005, 18:316-322.

17. Gupta P, Thombare R, Pakhan AJ, Singhal S: Cephalometric evaluation of the effect of complete dentures on retropharyngeal space and its effect on spirometric values in altered vertical dimension. ISRN Dent 2011, 2011:516969.

18. Huynh N, Emami E, Helman J, Chervin R: Interactions between sleep disorders and oral diseases. Oral Dis 2014, 20:236-245.

19. Endeshaw YW, Katz S, Ouslander JG, Bliwise DL: Association of denture use with sleep-disordered breathing among older adults. J Public Health Dent 2004, 64:181-183.

20. Ivanhoe JR, Cibirka RM, Lefebvre CA, Parr GR: Dental considerations in upper airway sleep disorders: a review of the literature. $J$ Prosthet Dent 1999, 82:685-698.

21. Kurtulmus H, Cotert HS: Management of obstructive sleep apnea with a mandibular and tongue advancement splint (MTAS) in a completely edentulous patient. A clinical report. J Prosthodont Off J Am Coll Prosthodont 2009, 18:348-352.

22. Nayar S, Knox J: Management of obstructive sleep apnea in an edentulous patient with a mandibular advancement splint: a clinical report. J Prosthet Dent 2005, 94:108-111.

23. Ancoli-Israel S, Kripke DF: Prevalent sleep problems in the aged. Biofeedback Self Regul 1991, 16:349-359.

24. Wolkove N, Elkholy O, Baltzan M, Palayew M: Sleep and aging: 1. Sleep disorders commonly found in older people. CMAJ 2007, 176:1299-1304.

25. Nguyen ATD, Jobin V, Payne R, Beauregard J, Naor N, Kimoff RJ: Laryngeal and velopharyngeal sensory impairment in obstructive sleep apnea. Sleep 2005, 28:585-593.

26. Hung $\mathrm{H}-\mathrm{C}$, Colditz G, Joshipura KJ: The association between tooth loss and the self-reported intake of selected CVD-related nutrients and foods among US women. Community Dent Oral Epidemiol 2005, 33:167-173.

27. Österberg T, Dey DK, Sundh V, Carlsson GE, Jansson J-O, Mellström D: Edentulism associated with obesity: a study of four national surveys of 16416 Swedes aged 55-84 years. Acta Odontol Scand 2010, 68:360-367.

28. Almeida FR, Furuyama RJ, Chaccur DC, Lowe AA, Chen H, Bittencourt LR, Frigeiro MLMA, Tsuda H: Complete denture wear during sleep in elderly sleep apnea patients - a preliminary study. Sleep Breath 2012, 16:855-863.

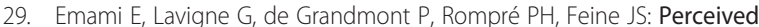
sleep quality among edentulous elders. Gerodontology 2012, 29:e128-e134.

30. Cumming CG, Wight C, Blackwell CL, Wray D: Denture stomatitis in the elderly. Oral Microbiol Immunol 1990, 5:82-85.

31. Emami $E$, Séguin J, Rompré $P H$, de Koninck $L$, de Grandmont $P$, Barbeau J: The relationship of myceliated colonies of Candida albicans with denture stomatitis: an in vivo/in vitro study. Int J Prosthodont 2007, 20:514-520.

32. Felton D, Cooper L, Duqum I, Minsley G, Guckes A, Haug S, Meredith P, Solie C, Avery D, Deal Chandler N, American College of Prosthodontists: Evidence-based guidelines for the care and maintenance of complete dentures: a publication of the American College of Prosthodontists. J Prosthodont 2011, 20(Suppl 1):S1-S12.

33. Sumi $Y$, Miura H, Michiwaki $Y$, Nagaosa S, Nagaya M: Colonization of dental plaque by respiratory pathogens in dependent elderly. Arch Gerontol Geriatr 2007, 44:119-124

34. Marcus PA, Joshi A, Jones JA, Morgano SM: Complete edentulism and denture use for elders in New England. J Prosthet Dent 1996, 76:260-266.

35. Emami $E$, de Grandmont $P$, Rompré PH, Barbeau J, Pan S, Feine JS: Favoring trauma as an etiological factor in denture stomatitis. J Dent Res 2008, 87:440-444.

36. Divaris K, Ntounis A, Marinis A, Polyzois G, Polychronopoulou A: Loss of natural dentition: multi-level effects among a geriatric population. Gerodontology 2012, 29:e192-e199.

37. Zomorodian K, Haghighi NN, Rajaee N, Pakshir K, Tarazooie B, Vojdani M, Sedaghat F, Vosoghi M: Assessment of Candida species colonization and denture-related stomatitis in complete denture wearers. Med Mycol 2011, 49:208-211.

38. ORBi: OCEBM Levels of Evidence Working Group - Oxford Centre for Evidence-Based Medicine 2011 Levels of Evidence - Traduction française In [http://orbi.ulg.ac.be/handle/2268/113937]

39. Arisaka H, Sakuraba S, Tamaki K, Watanabe T, Takeda J, Yoshida K: Effects of wearing complete dentures during sleep on the Apnea-Hypopnea Index. Int J Prosthodont 2009, 22:173-177.

40. Grimshaw J, Freemantle N, Wallace S, Russell I, Hurwitz B, Watt I, Long A Sheldon T: Developing and implementing clinical practice guidelines. Qual Health Care 1995, 4:55-64.

41. Sibbald B, Roland M: Understanding controlled trials: why are randomised controlled trials important? BMJ 1998, 316:201.

42. Folstein MF, Folstein SE, McHugh PR: 'Mini-Mental State'. A practical method for grading the cognitive state of patients for the clinician. $J$ Psychiatr Res 1975, 12:189-198.

43. Grizzle JE: The two-period change-over design and its use in clinical trials. Biometrics 1965, 21:467-480.

44. Anisimov W: Effects of unstratified and centre-stratified randomization in multi-centre clinical trials. Pharm Stat 2011, 10:50-59.

45. Kundt G, Glass A: Evaluation of imbalance in stratified blocked randomization: some remarks on the range of validity of the model by Hallstrom and Davis. Methods Inf Med 2012, 51:55-62.

46. Kundt G: Comparative evaluation of balancing properties of stratified randomization procedures. Methods Inf Med 2009, 48:129-134.

47. Lachin JM: Statistical properties of randomization in clinical trials. Control Clin Trials 1988, 9:289-311.

48. Ma Z, Hu F: Balancing continuous covariates based on Kernel densities. Contemp Clin Trials 2013, 34:262-269.

49. Matts JP, Lachin JM: Properties of permuted-block randomization in clinical trials. Control Clin Trials 1988, 9:327-344.

50. Signorini DF, Leung O, Simes RJ, Beller E, Gebski VJ, Callaghan T: Dynamic balanced randomization for clinical trials. Stat Med 1993, 12:2343-2350.

51. Zhang Y, Rosenberger WF, Smythe RT: Sequential monitoring of randomization tests: stratified randomization. Biometrics 2007, 63:865-872.

52. Corral-Peñafiel J, Pepin J-L, Barbe F: Ambulatory monitoring in the diagnosis and management of obstructive sleep apnoea syndrome. Eur Respir Rev Off J Eur Respir Soc 2013, 22:312-324.

53. Carra MC, Huynh NT, El-Khatib H, Remise C, Lavigne GJ: Sleep bruxism, snoring, and headaches in adolescents: short-term effects of a mandibular advancement appliance. Sleep Med 2013, 14:656-661.

54. American Academy of Sleep Medicine Task Force: Sleep-related breathing disorders in adults: recommendations for syndrome definition and measurement techniques in clinical research. The Report of an American Academy of Sleep Medicine Task Force. Sleep 1999, 22:667-689.

55. Bloom HG, Ahmed I, Alessi CA, Ancoli-lsrael S, Buysse DJ, Kryger MH, Phillips BA, Thorpy MJ, Vitiello MV, Zee PC: Evidence-based recommendations for the assessment and management of sleep disorders in older persons. J Am Geriatr Soc 2009, 57:761-789.

56. American Academy of Sleep Medicine: The International Classification of Sleep Disorders, Revised - Diagnotic and Coding Manual. 2001. http://www. esst.org/adds/ICSD.pdf

57. Tiihonen P, Hukkanen T, Tuomilehto H, Mervaala E, Töyräs J: Evaluation of a novel ambulatory device for screening of sleep apnea. Telemed E-Health 2009, 15:283-289

58. American Academy of Sleep Medicine: The AASM Manual for the Scoring of Sleep and Associated Events. In [http://www.aasmnet.org/ scoringmanual/default.aspx]

59. Johns MW: A new method for measuring daytime sleepiness: the Epworth Sleepiness Scale. Sleep 1991, 14:540-545

60. Slade AJSGD: Development and evaluation of the Oral Health Impact Profile. Community Dent Health 1994, 11:3-11.

61. Slade GD: Assessing change in quality of life using the Oral Health Impact Profile. Community Dent Oral Epidemiol 1998, 26:52-61.

62. Locker D, Slade G: Oral health and the quality of life among older adults: the oral health impact profile. J Can Dent Assoc 1993, 59:830-833. $837-838,844$

63. Heydecke G, Locker D, Awad MA, Lund JP, Feine JS: Oral and general health-related quality of life with conventional and implant dentures. Community Dent Oral Epidemiol 2003, 31:161-168. 
64. Emami $E$, de Grandmont $P$, Rompré $P$ : Oral health quality of life and physical health. Int I Health 2011, 1:157-170.

65. Nuckton TJ, Glidden DV, Browner WS, Claman DM: Physical examination: Mallampati score as an independent predictor of obstructive sleep apnea. Sleep 2006, 29:903-908.

66. Ware JE: SF-36 Physical and Mental Health Summary Scales: A User's Manual. The Health Institute, New England Medical Center; 1994. http://www. google.ca/search?hl=vi\&tbo=p\&tbm=bks\&q=inauthor:\%22Mark+Kosinski\% 22\&source $=$ gbs_metadata_r\&cad $=6$

67. Hopman WM, Towheed T, Anastassiades T, Tenenhouse A, Poliquin S, Berger C, Joseph L, Brown JP, Murray TM, Adachi JD, Hanley DA, Papadimitropoulos E: Canadian normative data for the SF-36 health survey. Canadian Multicentre Osteoporosis Study Research Group. CMAJ 2000, 163:265-271.

68. Ware JE, Sherbourne CD: The MOS 36-item short-form health survey (SF-36). I. Conceptual framework and item selection. Med Care 1992, 30:473-483.

69. Ware JE, Snow KK, Kosinski M, Gandek B, Institute NEMCHH: SF-36 Health Survey: Manual and Interpretation Guide. Boston, MA: The Health Institute, New England Medical Center; 1993.

70. Sumsion T: The Delphi technique: an adaptive research tool. Br J Occup There 1998, 61:153-156.

71. Emami E, Beauchamp A, Rompré P: Sleep stability in edentate elders [abstract]. J Dent Res 2012 2012, 91 (Special Issue B):163999.

72. Emami E, Heydecke G, Rompré PH, de Grandmont P, Feine JS: Impact of implant support for mandibular dentures on satisfaction, oral and general health-related quality of life: a meta-analysis of randomized-controlled trials. Clin Oral Implants Res 2009, 20:533-544.

73. Michaud P-L, de Grandmont P, Feine JS, Emami E: Measuring patient-based outcomes: is treatment satisfaction associated with oral health-related quality of life? J Dent 2012, 40:624-631.

74. Leon AC, Marzuk PM, Portera L: More reliable outcome measures can reduce sample size requirements. Arch Gen Psychiatry 1995, 52:867-871.

75. Sherrill JT, Sommers DI, Nierenberg AA, Leon AC, Arndt S, Bandeen-Roche K, Greenhouse J, Guthrie D, Normand S-L, Phillips KA, Shear MK, Woolson R: Integrating statistical and clinical research elements in intervention-related grant applications: summary from an NIMH workshop. Acad Psychiatry 2009, 33:221-228.

76. Putt $M$, Chinchilli VM: A mixed effects model for the analysis of repeated measures cross-over studies. Stat Med 1999, 18:3037-3058.

doi:10.1186/1745-6215-15-358

Cite this article as: Emami et al:: The effect of nocturnal wear of complete dentures on sleep and oral health related quality of life: study protocol for a randomized controlled trial. Trials 2014 15:358.

\section{Submit your next manuscript to BioMed Central and take full advantage of:}

- Convenient online submission

- Thorough peer review

- No space constraints or color figure charges

- Immediate publication on acceptance

- Inclusion in PubMed, CAS, Scopus and Google Scholar

- Research which is freely available for redistribution

Submit your manuscript at www.biomedcentral.com/submit
C Biomed Central 